\title{
МЕЖПОКОЛЕНЧЕСКИЕ СЧЕТА И ДЕМОГРАФИЧЕСКИЙ ДИВИДЕНД В РОССИИ
}

\author{
МИХАИЛ ДЕНИСЕНКО, ВЛАДИМИР КОЗЛОВ
}

\begin{abstract}
В предлагаемой статье представлена современная методология оценки вклада отдельных возрастных групп в производство и распределение национального дохода - национальные трансфертные (межпоколенческие) счета. Экономический жизненный цикл человека делится на стадии, которые определяются соотношением трудового дохода и потребления. В средних возрастах получаемый доход превышает текущее потребление. Возникает избыток или профицит ресурсов, который идет на покрытие дефицита дохода для обеспечения потребления в младших и старших возрастных группах. Оценки дефицита или профицита в отдельных возрастах выполнены для российского населения по состоянию на 2013 2. на основе построенньх по результатам обследований и административных источников возрастных профилей доходов и потребления. Дается оценка изменений дефищита жизненного цикла на перспективу при разных сценариях демографического развития. Возрастные профили доходов и потребления были использованы для оценки эффективной экономической поддержки и влияния демографических изменений в России на темпы экономического роста в ближайшем будущем.
\end{abstract}

Ключевые слова: жизненный иикл, национальные трансфертные счета, доход, потребление, старение, эффективная экономическая поддержка, демографический дивиденд.

\section{ВВЕДЕНИЕ}

В последние десятилетия мир переживает значительные демографические изменения, которые проявляются в снижении рождаемости, увеличении продолжительности жизни, интенсивной международной миграции и, как следствие, в трансформации возрастного состава населения. В одних странах, в которых демографический переход близок к завершению или завершился, идет процесс демографического старения. Устойчивое увеличение доли лиц в старших возрастах в общей численности населения является вызовом для этих стран, социальные институты которых сформировались в период «демографической молодости». В других странах, где рождаемость начала снижаться сравнительно недавно, увеличивается доля молодых трудоспособных возрастов и сокращается доля детей. При прочих равных условиях подобная оптимизация возрастной структуры может привести к получению демографического дивиденда, как это было недавно в Китае или других странах Юго-Восточной Азии.

МИХАИЛ БОРИСОВИЧ ДЕНИСЕНКО (mdenissenko@hse.ru), НАЦИОНАЛЬНЫЙ ИССЛЕДОВАТЕЛЬСКИЙ УНИВЕРСИТЕТ «ВЫСШАЯ ШКОЛА ЭКОНОМИКИ», РОССИЯ.

ВЛАДИМИР АЛЕКСАНДРОВИЧ КОЗЛОВ (vakozlov@ @se.ru), НАЦИОНАЛЬНЫЙ ИССЛЕДОВАТЕЛЬСКИЙ УНИВЕРСИТЕТ «ВЫСШАЯ ШКОЛА ЭКОНОМИКИ», РОССИЯ.

СТАТЬЯ ПОДГОТОВЛЕНА В РАМКАХ ПРИКЛАДНОГО ПРОЕКТА НИУ ВШЭ ТЗ 148 «ВКЛЮЧЕНИЕ РОССИИ В СИСТЕМУ МЕЖДУНАРОДНЫХ СОПОСТАВЛЕНИЙ ПО НАЦИОНАЛЬНЫМ ПОКОЛЕНЧЕСКИМ СЧЕТАМ».

СТАТЬЯ ПОСТУПИЛА В РЕДАКЦИЮ В ОКТЯБРЕ 2018 г. 
По некоторым оценкам, демографический дивиденд в Восточной Азии объясняет от одной четвертой до двух пятых экономического роста в 1980-1990-х годах [Bloom, Canning, Sevilla 2003: 45]. Но возможен и такой вариант развития, при котором бедные страны не успеют воспользоваться возможностями, которые предоставляет демографический переход, и извлечь демографический дивиденд до того, как начнется процесс старения населения.

Найти ответы на демографические вызовы - значит преодолеть возможные проблемы и конфликты, с одной стороны, и реализовать открывающиеся возможности для развития, с другой. В этом состоит одна из главных задач социально-экономической политики. Но для ее обоснования и реализации необходимо корректно измерять последствия изменений в возрастном составе населения. Поиск таких индикаторов является одной из важных задач экономико-демографических исследований. Однако принятые в современном мире стандартные индикаторы экономического развития разрабатываются в основном по отношению ко всему населению и не отражают вклад отдельных возрастных групп или поколений в совокупное производство и потребление. Если данные о возрастных характеристиках потребления, доходов, производительности труда в ряде стран систематически собираются и разрабатываются, то о закономерностях перераспределения доходов и ресурсов между поколениями известно недопустимо мало. Трансфертные системы, функционирование которых опосредовано институтом семьи, государством или рынком, под влиянием упомянутых выше демографических изменений сегодня сами находятся в состоянии реформирования.

Интерес к оценке последствий демографических изменений в России за последние годы существенно вырос. Многие вопросы, связанные с организацией образования, социального обеспечения и здравоохранения, нерешенные в прошлом, в условиях усиливающегося процесса старения грозят обостриться в уже недалеком будущем. Кроме того, интерес к экономико-демографической тематике повышают продолжающееся сокращение численности населения в рабочих возрастах, ускоренное увеличение доли лиц в старших и на этом фоне вероятное усиление миграционных потоков. Таким образом, задача построения адекватных индикаторов, отражающих последствия старения населения в России, представляется крайне важной в самое ближайшее время.

В данной статье мы остановимся на двух индикаторах, которые позволяют оценить влияние изменений в возрастном составе населения на экономическое развитие, и представим их оценки для Российской Федерации. Речь идет о показателе «дефицит жизненного цикла» (life cycle deficit) и о показателе «эффективная экономическая поддержка» (effective economic support). Оба этих показателя получили свое обоснование в рамках новой методологии анализа перераспределения ресурсов между поколениями системы национальных трансфертных (межпоколенческих) счетов. В статье кратко рассматриваются базовые положения методологии их построения. Эта часть работы дополняется оценками ряда показателей системы национальных трансфертных счетов для России за 2013 г. В завершающей части представлены оценки дефицита жизненного цикла и эффективной экономической поддержки, которые отражают влияние изменений в возрастном составе населения России на экономику страны в ближайшем будущем. 
Начинается же статья кратким обзором истории включения возрастных структур в экономические модели.

\section{ВОЗРАСТНЫЕ СТРУКТУРЫ НАСЕЛЕНИЯ В ЭКОНОМИЧЕСКИХ ИССЛЕДОВАНИЯХ}

Многочисленные исследования роли возрастного состава и его изменений в экономическом развитии со временем объединились в направление, которое получило название «Экономика поколений» (Generational economy). Согласно одному из определений, экономика поколений изучает: 1) социальные институты и экономические механизмы, посредством которых поколения или возрастные группы производят, потребляют, перераспределяют и сберегают ресурсы; 2) экономические потоки между поколениями или возрастными группами; 3) явные и неявные контракты, которые управляют межпоколенными потоками; 4) доходы и потребление отдельных поколений и возрастных групп [Lee, Mason 2011: 7]. Начальный период в истории исследований по данной тематике отличался тем, что работы, выполненные демографами, в основном оставались неизвестными экономистам, как и работы ученых из бывших социалистических стран были terra incognita для их западных коллег.

Возникновение «Экономики поколений» как научного направления в западной литературе связывают с именами двух нобелевских лауреатов - Пола Самуэльсона и Франко Модильяни.

Макроэкономика поколений начинается с работы Самуэльсона и предложенной им модели «пересекающихся поколений» (overlapping generation) [Барро, Сала-и-Мартин 2004: 252]. В своем исследовании равновесной нормы процента П. Самуэльсон предположил, что жизнь населения делится на два периода: трудовой (в возрасте от 20 до 65 лет) и пенсионный (в возрасте от 65 лет и старше). В трудовом периоде одна часть средств уходит на потребление (в том числе детей), а другая часть - на сбережения для обеспечения потребления в старости. В старших возрастах человек потребляет за счет своих сбережений, а также за счет возврата предоставленных когда-то кредитов более молодым поколениям. Потребление сбережений П. Самуэльсон назвал «трансфертами во времени» [Samuelson 1958: 471].

Впоследствии модель пересекающихся поколений усложнилась, в нее включались разные формы межпоколенческих трансфертов. В качестве примера приведем несколько исследований. Так, в следующей после П. Самуэльсона заметной работе еще один нобелевский лауреат Питер Даймонд [Diamond 1965], используя эту модель, показал значимость национального долга и солидарной пенсионной системы для оптимизации уровня потребления в обществе. В свою очередь Р. Барро, обращаясь к модели пересекающихся поколений, высказал гипотезу, что внутрисемейные трансферты нейтрализуют перераспределительные эффекты общественных трансфертов [Barro 1974]. В 1978 г. У. Артур и Дж. Макниколл объединили демографические модели возрастной структуры и модель пересекающихся поколений Самуэльсона. Это позволило им установить значимость темпов роста и возрастного состава населения для объемов 
сбережений и межпоколенческих трансфертов [Arthur, McNicoll 1978]. В 1988 г. вышла коллективная монография «Экономика изменений возрастной структуры в развитых странах», в которой затрагиваются разные аспекты старения населения: экономический рост, когортные эффекты в размерах заработков, влияние на рынок труда и на сектор домашних хозяйств, демографические особенности пенсионных систем и др. [Lee, Arthur, Rodgers 1988]. Особенно отметим главу Р. Уиллиса, который попытался интегрировать микроэкономические модели жизненного цикла индивидуума и домохозяйства, демографического поведения в модель пересекающихся поколений [Willis 1988].

Работа Ф. Модильяни и Р. Брамберга положила начало микрооснованиям экономики поколений. В ней была сформулирована концепция экономического жизненного цикла и обоснован тезис о взаимосвязи уровня потребления, сбережений и трансфертов между поколениями [Modigliani, Brumberg 1954]. Проблемы межпоколенческих взаимодействий через призму концепции жизненного цикла рассматривались во многих исследованиях. Так, например, М. Фельдстейн, опираясь на модель экономического жизненного цикла, одним из первых предположил, что общественные пенсионные программы уменьшают склонность к сбережениям [Feldstein 1974: 910]. Л. Котликофф и Л. Саммерс [Kotlikoff, Summers 1981], обратившись к возрастным профилям заработков и потребления, установили, что важным фактором сбережений и накопления богатства являются межпоколенческие трансферты, которые осуществляются, по их мнению, с целью поддержки детей или родителей. Несколько иную точку зрения высказал на этот счет один из авторов концепции экономического жизненного цикла Ф. Модильяни, который утверждал, что желание поддержать уровень потребления после выхода на пенсию объясняет накопление сбережений и капитала в США [Modigliani 1988].

Вместе с тем следует отметить, что еще в первой четверти XX века выдающимся русским ученым А. Чаяновым была высказана и реализована идея построения поколенческих экономических балансов на основе возрастных профилей производства и потребления [Чаянов 1989]. Изучая бюджеты крестьянских хозяйств, он установил тесную взаимосвязь между фазами жизненного цикла крестьянской семьи, размерами ее хозяйственной деятельности и потребления, выявил вклад отдельных поколений в развитие крестьянских хозяйств на отдельных фазах его жизненного цикла.

В Европе в то же время, что и в США, также шаг за шагом шел процесс анализа влияния демографических изменений на экономическое развитие. Так, идеи французской экономико-демографической школы относительно межпоколенческих взаимодействий, последствий старения населения в 1960-х годах были обобщены в работе А. Сови «Общая теория населения» [Сови 1977]. Необходимо отметить уникальные для своего времени (1960-1970-е годы) работы венгерского демографа Э. Валковича [1971]. Для оценки влияния возрастных структур он предложил метод экономических возрастных пирамид. По результатам обследований он определял возрастные профили доходов и потребления в Венгрии, а на их основе - периоды дефицита или избытка ресурсов на отдельных этапах жизненного цикла. Возрастные пирамиды или структуры исчислялись путем умножения полученных повозрастных показателей на численность населения соответствующих возрастных групп. Сравнение экономических пирамид за ряд лет позволяет оценить эффект 
изменения возрастной структуры на совокупные показатели производства, потребления, сбережений и др.

В 1970-1980-х годах австралийский демограф Дж. Колдуэлл, основываясь на идеях А. Чаянова, развивал теорию демографического перехода, ключевым элементом которой стал анализ направлений потоков благ между поколениями [Caldwell 1982]. Межпоколенные отношения в традиционном обществе складывались в пользу старших возрастов, поскольку система межродственной поддержки была направлена в их сторону, а экономическая активность начиналась в детском возрасте. Согласно результатам ряда исследований Дж. Колдуэлла и его последователей, экономическая ценность детей благодаря «чистому потоку благ» от них для родителей была высокой. Трансфертная система перераспределения ресурсов традиционного общества, сложившаяся в условиях высокой смертности, обеспечивала высокую рождаемость.

В СССР в 1986 г. была опубликована работа Е. Андреева и Л. Дарского, посвящённая экономико-демографическим процессам в реальных поколениях [Андреев, Дарский 1986]. Основываясь на модели стабильного населения, а также на некоторых идеях Б. Урланиса [Урланис 1971; 1976], они оценили объемы произведенных и потребленных благ разными поколениями в зависимости от темпов прироста производительности труда, уровня смертности и темпов прироста населения. Андреев и Дарский показали, что возможна ситуация отрицательного экономического баланса поколений, т.е. превышения потребления над объемом произведенных благ. Это обусловлено тем, что период трудовой деятельности в 1970-1980-е годы уменьшался вследствие удлинения периода обучения и развития системы пенсионного обеспечения. Они соглашались с Урланисом, что систематический отрицательный баланс поколений необязательно связан с уменьшением национального богатства. Этот баланс может покрываться за счет других поколений, в том числе более молодых, имеющих более высокую производительность. При этом баланс гипотетического поколения остается положительным. Понятие баланса здесь фактически соответствует понятию дефицита жизненного цикла, принятого в зарубежной литературе.

Результаты многочисленных и многолетних исследований, в конечном итоге, привели ученых к заключению, что задачи оценки последствий демографических изменений для экономики и государственной политики следует решать посредством балансовых уравнений перераспределения ресурсов между поколениями (возрастными группами), сочетающих в себе аналитические методы демографии и экономической теории. Работа по созданию межпоколенческих балансов в рамках системы национальных счетов началась в 1980-х годах. Заслуга по созданию современной системы принадлежит американцам - демографу Рональду Ли и экономисту Эндрю Мэйсону [D’Albis, Moosa 2015]. Так, еще в 1980 г. Р. Ли обобщил наработки исследователей за двадцатилетний период. Там же он предпринял одну из первых попыток оценки влияния изменений в возрастной структуре через межпоколенные трансферты на экономический рост [Lee 1980]. Э. Мэйсон в своей работе 1988 г. показал ценность межпоколенческого подхода для изучения сбережений [Mason 1988]. В 1994 г. Р. Ли, анализируя последствия старения населения, попытался объединить модели воспроизводства населения с экономическими моделями и исследовательскими темами, в том числе с моделями пересекающихся поколений, оптимального роста населения, сбережений и жизненного цикла, с 
бухгалтерией поколений (о ней будет сказано ниже), а также с изучением реакции населения на введение общественных трансфертных программ и др. [Lee 1994].

В своих последующих работах Р. Ли и Э. Мэйсон развили методику построения и анализа балансов (счетов) экономических потоков с учетом возрастного состава населения. Ими была высказана идея построения возрастных балансов бюджетов времени. Впоследствии эта идея была реализована в рамках исследовательского проекта «Национальные трансфертные счета». Возрастные профили потребления и доходов в дальнейшем использовали для построения моделей накопления капитала и перераспределения богатства, развития системы. Используя возрастные профили налогов и льгот, Р. Ли и Ш. Тулджапуркар [Lee, Tuljapurkar 2000] построили долговременный прогноз финансового развития системы социального обеспечения в США в условиях демографического старения, а Р. Ли и Т. Миллер оценили долговременные фискальные последствия иммиграции для США [Lee, Miller 2000]. Группа исследователей (А. Бомье, Р. Ли и др.) определила, какие из поколений 1850-2090 гг. рождения в США являются выигравшими, а какие проигравшими в результате перераспределения ресурсов через канал общественных межпоколенческих трансфертов [Bommier et al. 2010].

Широкий научный и общественный интерес к оценке последствий демографических изменений, а также результаты многочисленных научных изысканий привели к тому, что в 2002 г. под научным руководством Р. Ли и А. Мэйсона был запущен международный проект по разработке методологии построения системы национальных межпокленческих (трансфертных) счетов и их применению. В число первых участников проекта помимо развитых стран (США, Франция, Япония) входили и развивающиеся страны (Бразилия, Индонезия, Тайвань, Чили), которые столкнулись с быстрыми изменениями в рождаемости, смертности и возрастном составе населения. Первоначально проект поддерживался Национальным институтом старения США. Но спустя несколько лет к поддержке проекта присоединился Фонд ООН по проблемам народонаселения, затем Еврокомиссия, Центр по развитию международных исследований Канады, Отдел народонаселения секретариата ООН. В настоящее время в проекте участвует 94 страны, включая Россию ${ }^{1}$.

В конце 1990 - начале 2000-х годов американский демограф Дэвид Блум с коллегами показали, что «чудо» быстрого экономического роста стран Азии (Китай, Таиланд, Тайвань, Южная Корея) во многом объясняется изменениями в возрастном составе населения [Bloom, Williamson 1998; Bloom, Canning, Malaney 2000; Bloom, Canning, Sevilla 2003]. В результате быстрого падения уровня рождаемости увеличилась доля лиц в трудоспособных возрастах и уменьшилась демографическая нагрузка. Полученный выигрыш был назван демографическим дивидендом. С тех пор понятие «демографический дивиденд» стало одним из центральных в экономико-демографических исследованиях [Ли, Мэйсон 2006]. Новые подходы к его оценке, а также к оценке коэффициентов поддержки с учетом возрастных особенностей получения дохода и потребления были разработаны в рамках системы национальных трансфертных счетов [Prskawetz, Sambt 2014; Mason et al. 2017].

\footnotetext{
${ }^{1}$ Россию представляет Национальный исследовательский университет «Высшая школа экономики». 
Отметим, что помимо национальных трансфертных счетов, к которым обращаются авторы данной статьи, существуют и другие методы оценки перераспределения ресурсов между поколениями. Например, в начале 1990-х годов американские экономисты и демографы Л. Котликофф, А. Ауэрбах и Дж. Гокхейл для оценки последствий демографического старения и финансовой эффективности действующих государственных программ, перераспределяющих доходы между поколениями (в первую очередь пенсионных программ), предложили метод так называемой межпоколенной бухгалтерии (Generational Accounting) [Kotlikoff 1992; Auerbach, Gokhale, Kotlikoff 1994]. В 2013 г. в Институте экономической политики имени Е.Т. Гайдара было проведено экономикодемографическое исследование текущего и перспективного состояния государственных финансов в России «Оценка бюджетного разрыва в РФ» при участии Л. Котликофф 2 . По оценке специалистов, действующая фискальная политика не может обеспечить устойчивость бюджетной системы в течение длительного срока во многом из-за старения населения, которое будет вызывать рост расходов на пенсионное обеспечение и медицинские услуги. В итоге бюджетный разрыв, по которому и оценивалась устойчивость государственных финансов, в России к 2015 г. должен был возрасти до 11,8-14,1\%. Но проблема была не только в старении населения, но и в вероятном снижении доходов бюджета от экспорта углеводородов (эффект примерно в 2 раза сильнее демографического).

\section{МЕЖПОКОЛЕНЧЕСКИЕ СЧЕТА}

Экономическую систему можно представить в виде потоков благ между людьми и различными институтами, среди которых важное место занимают потоки между поколениями или межпоколенческие трансферты. Однако в главной системе описания и анализа макроэкономических процессов в странах мира - системе национальных счетов $(\mathrm{CHC})^{3}$ - перераспределение ресурсов между возрастными группами (поколениями) не отражается. Таким образом, эта система никак не увязана с эпохальными демографическими изменениями, которые происходят на рубеже XX и XXI веков как в развитых (демографическое старение), так и развивающихся (снижение рождаемости) странах мира. Авторами идеи увязать СНС с демографическими процессами являются уже упоминавшиеся экономист Эндрю Мэйсон и демограф Рональд Ли. В итоге ими была разработана концепция построения Национальных трансфертных (межпоколенческих)

\footnotetext{
${ }^{2}$ Сайт проекта: URL: http://www.iep.ru/ru/ocenka-byudzhetnogo-razryva-v-rf-russia-s-fiscal-gap.html. Ocновные результаты были опубликованы позднее в статье [Горюнов и др. 2015].

${ }^{3}$ Система национальных счетов возникла около 50 лет тому назад в наиболее развитых в экономическом отношении странах в связи с потребностью в информации, необходимой для анализа состояния экономики, формирования экономической политики и принятия мер по регулированию рыночной экономики. Концептуально эта система гармонизирована с платежным балансом и рядом других разделов макроэкономической статистики. Суть СНС сводится к формированию обобщающих показателей развития экономики на различных стадиях процесса воспроизводства и взаимной увязке этих показателей между собой. Каждой стадии воспроизводства (стадии производства, первичного распределения доходов, вторичного распределения доходов, использования на конечное потребление и накопление и др.) соответствует специальный счет или группа счетов. В системе национальных счетов отражаются счета потоков, т.е. движение потоков товаров, услуг и доходов через все стадии (от производства до использования), а также изменение нефинансовых активов и финансовых активов и обязательств (См.: [Система национальных счетов 2012]).
} 
счетов (National Transfer Accounts или сокращенно NTA), которые в своей полной форме представляют собой системное и комплексное отображение существующих экономических потоков как потоков между возрастными группами [Lee, Mason 2011; United Nations 2013].

Внешне система национальных трансфертных счетов в полной форме представляет собой распределение ряда показателей национальных счетов по однолетним возрастным группам. Но между системами СНC и NTA имеются различия. В частности, единицей анализа в межпоколенческих счетах является индивид, а не домохозяйство. Хотя в рамках домохозяйств осуществляется совместное потребление, но все же, по мнению авторов NTA, в значительной части случаев потребление носит индивидуальный характер. Вместе с тем существуют экономические потоки, которые прямо не могут быть распределены по возрастным группам: а) потоки между институтами, например, между корпорациями и государством; б) ряд потоков общественных благ, например, расходы на оборону, государственный аппарат, судебную систему; в) многие потоки, которые в статистике увязываются не с индивидуумом, а с домохозяйствами. На практике при построении национальных трансфертных счетов для распределения этих потоков между возрастными группами прибегают к разного рода предположениям и/или моделям.

Социальные институты в концепции национальных трансфертных счетов выступают исключительно как посредники обменов между возрастными группами. Например, прибыль фирмы рассматривается через призму возраста их собственника, трансферты правительства - через возраст налогоплательщиков и получателей разного рода пособий и льгот. Всего выделяется три группы институтов: 1) частные институты: корпорации, домохозяйства, некоммерческие организации; 2) общественные или государственные институты; 3) остальной мир, с которым связан приток или отток благ из-за рубежа.

В системе трансфертных счетов используются категории «трудовой доход» и «доход от активов», которые не определены в системе национальных счетов, но определяются на их основе. Согласно методологии построения трансфертных счетов, трудовой доход, доход от капитала и потребление оцениваются до выплат налогов и субсидий на продукты и производство.

Согласно методологии построения национальных трансфертных счетов, трудовой доход является источником ресурсов для потребления. В отличие от национальных счетов, все остальные формы индивидуальных доходов (рента, проценты, пенсии и др.) попадают в категорию реаллокаций, т.е. являются результатом перераспределения ресурсов с целью удовлетворения настоящего или будущего потребления. Трудовой доход в свою очередь распадается на две компоненты: оплата труда наемных работников (включая разного рода бонусы от работодателя, например, стоимость социального пакета) и доход от самозанятости. Доход от самозанятости исчисляется как две трети от смешанного дохода в национальных счетах.

Центральным моментом концепции национальных трансфертных счетов является экономический жизненный цикл, который отражает прежде всего особенности возрастных моделей потребления и получения дохода. На отдельных этапах жизненного цикла (в детстве и юности, в средних и старших возрастах) материальные потребности человека и возможности их удовлетворения, создаваемые его трудом, могут не совпадать. 
Так возникает дефицит ресурсов для потребления на этапах детства и старости и их избыток (профицит) - в средних возрастах. Этот дефицит покрывается с помощью механизмов перераспределения (реаллокации) ресурсов от возрастных групп, в которых имеется их избыток, в возрастные группы, в которых имеется их недостаток, в форме межпоколенческих трансфертов и передачи ресурсов на основе активов (asset-based reallocations) [United Nations 2013: 26, 31]. Механизмы перераспределения и соответствующие потоки ресурсов в зависимости от институтов, между которыми они осуществляются, подразделяются на частные и общественные.

Межпоколенческие трансферты представляют собой материальные ресурсы или услуги, переданные безвозмездно от представителей старшего поколения младшему (нисходящие трансферты) и от младшего поколения старшему (восходящие трансферты). Категория «трансферты» в системе национальных трансфертных счетов трактуется очень широко. В них включаются все безвозмездные потоки благ между индивидами, включая социальные выплаты и услуги от государства, налоговые платежи и отчисление на социальное страхование, трансферты между домохозяйствами и внутри домохозяйств. Следует заметить, что аналогов последних двух видов трансфертов в системе национальных счетов нет, и они оцениваются по другим источникам информации. Учет трансфертов внутри домохозяйств и подходы для их оценки - одно из важных научнопрактических нововведений, получивших обоснование в рамках концепции национальных трансфертных счетов.

Возрастное перераспределение на основе активов реализуется во времени в виде накопления сбережений и их расходования, а также доходов от активов по мере перехода человека в старшую возрастную группу. Так, сбережения делаются на протяжении всей трудовой жизни, а расходуются после выхода на пенсию. В юности человек получает кредиты на образование, за которые расплачивается после окончания университета. Покупка облигаций, акций, товаров длительного пользования, жилья, земли, страховки, потребительские кредиты и др. - все это примеры перераспределения на основе активов.

Экономические потоки в системе NTA помимо того, что подразделяются на общественные и частные, также распределяются по основным целям потребления и назначения трансфертов: образование, здравоохранение, государственные пенсии и др.

Фактически система национальных межпоколенческих счетов призвана ответить на вопрос, каким образом покрывается дефицит, возникающий на разных стадиях жизненного цикла. Экономический жизненный цикл выражается следующим балансовым уравнением, увязывающим основные потоки системы межпоколенческих счетов (формула 1): 


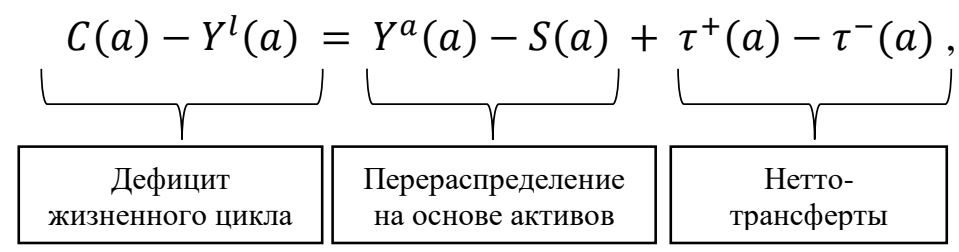

где:

$a$ - возраст;

$C(a)$ - потребление;

$Y^{l}(a)$ - трудовой доход;

$Y^{a}(a)$ - доход от активов;

$S(a)$ - сбережения;

$\tau^{+}(a)$ - полученные трансферты;

$\tau^{-}(a)$ - переданные трансферты.

Положительное значение этого равенства свидетельствует о дефиците ресурсов в данном возрасте, отрицательное - об их избытке или профиците. Следует отметить, что оценки национальных трансфертных счетов строятся за отдельные календарные годы, а возрастные распределения экономических показателей интерпретируются в терминах условных поколений. Но в последнее время по мере накопления информации предпринимаются попытки построения трансфертных счетов для реальных поколений [Temple, Rice, McDonald 2017].

\section{АГРЕГИРОВАННЫЕ ТРАНСФЕРТНЫЕ СЧЕТА}

Построение национальных трансфертных счетов начинается со сбора статистической информации по трем направлениям:

1) численность возрастных групп населения страны. Если трансфертные счета строятся для отдельных социально-демографических групп (половых, образовательных, городсело, мигранты и др.), то в таких случаях необходим возрастной состав этих групп;

2) национальные счета, содержащие базовую информацию об экономических потоках, которые будут распределяться по возрасту. На основе показателей национальных счетов рассчитываются агрегированные показатели (макроконтроллеры) доходов, потребления, трансфертов, доходов от активов и сбережений межпоколенческих счетов;

3) национально-репрезентативные обследования домашних хозяйств и административные источники информации (налоговые службы, казначейство, министерство образования и др.). По данным из этих источников оцениваются возрастные профили экономических показателей (в расчете на душу населения) для распределения по возрастным группам (поколениям) агрегированных показателей и окончательного построения трансфертных счетов. 
Опираясь на соответствующие источники данных, авторы статьи предприняли попытку построить национальные трансфертные счета и оценить дефицит жизненного цикла в России за 2013 г. Этот год был выбран неслучайно для начала работы по созданию системы NTA: этот год был последним перед финансово-экономическим кризисом, начавшимся в конце 2014 г., и введением режима санкций по отношению к России со стороны западных стран. Также принимался во внимание и тот факт, что с 2011 г. Росстат перешел на модернизированную методологию построения национальных счетов [Система национальных счетов 2012; Национальные счета России 2013].

На первом этапе были оценены значения агрегированных показателей (макроконтроллеры) потоков ресурсов в системе национальных трансфертных счетов 4 . Результаты оценки представлены в таблице 1. По аналогии с системой национальных счетов и в зависимости от задействованных институтов эти результаты оформлены в виде следующих счетов:

- счет жизненного цикла;

- счет общественного перераспределения благ между возрастными группами;

- счет частного перераспределения благ между возрастными группами 5 .

В данной статье основное внимание уделено счету жизненного цикла. Его компоненты (возрастные профили доходов и потребления) позволяют перейти к уточненным оценкам коэффициентов поддержки и демографического дивиденда, отражающих влияние изменений в возрастном составе населения России на ее экономическое развитие.

\section{ПОСТРОЕНИЕ ВОЗРАСТНЫХ ПРОФИЛЕЙ}

Далее главной задачей становится распределение агрегированных показателей потоков по поколениям, т.е. получение так называемых возрастных профилей макропоказателей системы национальных трансфертных счетов. Профили строятся по однолетним возрастным группам. Эта задача решается в два действия.

Первое заключается в том, что по данным обследований или административных источников, содержащих информацию о возрасте респондентов или пользователей услугами, строятся первичные возрастные профили, отражающий уровень подушевого потребления, трудовых доходов, трансфертов или сбережений. Как отмечалось выше, в обследованиях значительная часть информации привязывается не к индивидам, а к домохозяйствам, в которых они проживают. В связи с этим возникает проблема перехода от оценок по домохозяйствам к индивидуальным оценкам, поскольку единицей наблюдения в межпоколенческих счетах является индивид. Для решения этой проблемы

\footnotetext{
4 Детальная методика перехода от CHC к NTA изложена в Руководстве по построению и анализу национальных трансфертных счетов [United Nations 2013].

${ }^{5}$ В таблице 1 отсутствуют оценки объемов трансфертов между домохозяйствами и внутри них, которые не учитываются в СНС. Они выполняются по результатам обследований. В настоящее время ведется работа по уточнению модели этих трансфертных потоков.
} 
часто используются два подхода: 1) членам домохозяйств присваиваются потребительские веса или все приписывается главе домохозяйств (например, налоги или доход с ренты); 2) используются статистические методы (регрессии) для распределения той или иной величины между членами домохозяйств.

\section{Таблица 1. Агрегированные показатели (макроконтроллеры) системы национальных трансфертных счетов России в 2013 г., млрд руб.}

\begin{tabular}{|c|c|c|c|c|c|}
\hline \multicolumn{2}{|c|}{$\begin{array}{c}\text { Счет дефицита (+) / профицита (-) } \\
\text { жизненного цикла }\end{array}$} & \multicolumn{2}{|c|}{$\begin{array}{l}\text { Счет перераспределения } \\
\text { общественных ресурсов }\end{array}$} & \multicolumn{2}{|c|}{$\begin{array}{c}\text { Счет перераспределения } \\
\text { частных ресурсов }\end{array}$} \\
\hline название & объем & название & объем & название & объем \\
\hline $\begin{array}{l}\text { Дефицит } \\
\text { жизненного цикла }\end{array}$ & 3473 & $\begin{array}{l}\text { Общественное } \\
\text { перераспределение }\end{array}$ & 1224 & $\begin{array}{l}\text { Частное } \\
\text { перераспределение }\end{array}$ & 2249 \\
\hline Потребление & 43010 & $\begin{array}{l}\text { Чистые общественные } \\
\text { трансферты: }\end{array}$ & 245 & $\begin{array}{l}\text { Чистые частные } \\
\text { трансферты: }\end{array}$ & -543 \\
\hline $\begin{array}{l}\text { Общественное } \\
\text { потребление: }\end{array}$ & 13552 & $\begin{array}{l}\text { на образование: } \\
\text { приток }\end{array}$ & 1817 & $\begin{array}{l}\text { между } \\
\text { домохозяйствами: } \\
\text { приток }\end{array}$ & $\begin{array}{r}\text { Нет в } \\
\text { СHC }\end{array}$ \\
\hline услуг образования & 1817 & $\begin{array}{l}\text { на образование: } \\
\text { отток }\end{array}$ & 1817 & $\begin{array}{l}\text { между } \\
\text { домохозяйствами: } \\
\text { отток }\end{array}$ & $\begin{array}{r}\text { Нет в } \\
\text { CHC }\end{array}$ \\
\hline $\begin{array}{l}\text { услуг } \\
\text { здравоохранения }\end{array}$ & 2050 & $\begin{array}{l}\text { на здравоохранение: } \\
\text { приток }\end{array}$ & 2051 & $\begin{array}{l}\text { внутри } \\
\text { домохозяйств: } \\
\text { приток }\end{array}$ & $\begin{array}{l}\text { Нет в } \\
\text { CHC }\end{array}$ \\
\hline иное & 9684 & $\begin{array}{l}\text { на здравоохранение: } \\
\text { отток }\end{array}$ & 2051 & $\begin{array}{l}\text { внутри } \\
\text { домохозяйств: отток }\end{array}$ & $\begin{array}{r}\text { Нет в } \\
\text { CHC }\end{array}$ \\
\hline $\begin{array}{l}\text { Частное } \\
\text { потребление: }\end{array}$ & 29458 & на пенсии: приток & 5250 & $\begin{array}{l}\text { Частное } \\
\text { перераспределение на } \\
\text { основе активов: }\end{array}$ & 2793 \\
\hline услуг образования & 244 & на пенсии: отток & 5250 & $\begin{array}{l}\text { чистые доходы от } \\
\text { капитала }\end{array}$ & $\begin{array}{r}10 \\
946\end{array}$ \\
\hline $\begin{array}{l}\text { услуг } \\
\text { здравоохранения }\end{array}$ & 1173 & $\begin{array}{l}\text { другие в натуральной } \\
\text { форме: приток }\end{array}$ & 9684 & $\begin{array}{l}\text { вмененные доходы } \\
\text { собственников жилья }\end{array}$ & 5287 \\
\hline иное & 28041 & $\begin{array}{l}\text { другие в натуральной } \\
\text { форме: отток }\end{array}$ & 9684 & $\begin{array}{l}\text { чистые доходы от } \\
\text { собственности }\end{array}$ & -5107 \\
\hline Трудовой доход: & 39536 & $\begin{array}{l}\text { другие в денежной } \\
\text { форме: приток }\end{array}$ & 3595 & $\begin{array}{l}\text { чистые частные } \\
\text { сбережения }\end{array}$ & 8333 \\
\hline $\begin{array}{l}\text { оплата труда } \\
\text { наемных } \\
\text { работников }\end{array}$ & 11 & $\begin{array}{l}\text { другие в денежной } \\
\text { форме: отток }\end{array}$ & 3350 & & \\
\hline $\begin{array}{l}\text { доход от } \\
\text { самозанятости }\end{array}$ & 5725 & $\begin{array}{l}\text { Перераспределение в } \\
\text { форме активов }\end{array}$ & 979 & & \\
\hline & & $\begin{array}{l}\text { чистые доходы от } \\
\text { капитала }\end{array}$ & -51 & & \\
\hline & & $\begin{array}{l}\text { чистые доходы от } \\
\text { собственности } \\
\text { чистые }\end{array}$ & 2981 & & \\
\hline & & $\begin{array}{l}\text { общественные } \\
\text { сбережения }\end{array}$ & 1951 & & \\
\hline
\end{tabular}

Источник: Построено авторами совместно с сотрудниками института «Центр развития»

НИУ ВШЭ А.Г Назаровой и А.В. Чернявским.

Для построения первичных возрастных профилей использовали следующие источники данных:

- обследования домохозяйств (для получения профилей доходов, частного потребления, в том числе услуг здравоохранения): Российский мониторинг экономического 
положения и здоровья НИУ ВШЭ (РМЭЗ), Обследование доходов населения и участия в социальных программах Росстата;

- опрос НИУ ВШЭ в рамках Мониторинга экономики образования «Обследования в образовательных организациях, реализующих программы различных ступеней обучения» (для получения профилей частного потребления услуг образования);

- административные данные (для получения возрастных профилей пользователей общественными услугами систем здравоохранения и образования): Федеральное Казначейство, Фонд обязательного медицинского страхования, Министерство образования.

Для оценки общественного потребления, отличающегося от образования и здравоохранения отсутствием явной возрастной составляющей (оборона, содержание госаппарата, охрана общественного порядка и др.), использовали предположение о его равномерном распределении в расчете на человека по возрастным группам. Подобный подход применялся при построении трансфертных счетов, например, в США.

Второе действие заключается в преобразовании первичных профилей в профиль, соответствующий полученным ранее макроконтроллерам (агрегированный показатель, полученный из национальных счетов). Новый, вторичный, профиль и является непосредственной частью национальных трансфертных счетов. Эта задача решается с помощью введения специального коэффициента пропорциональности $\Theta$, который «подгоняет» значения первичных профилей к значениям макроконтроллеров. Коэффициент пропорциональности рассчитывается как отношение величины макроконтроллера к агрегированной оценке величины этого же показателя, рассчитанного как сумма произведений численности возрастных групп на соответствующее значение показателя в расчете на душу населения из первичного профиля (формула 2):

$$
\Theta=\frac{X}{\sum x(a) N(a)}
$$

где:

$a$ - возраст;

$N(a)$ - численность населения в возрасте $a$;

$X$ - макроконтроллер;

$x(a)$ - возрастной первичный профиль показателя $X$ (в расчете на душу населения).

Умножая коэффициент пропорциональности (2) на показатели первичного возрастного профиля, получаем возрастной профиль национальных трансфертных счетов (NTA) в расчете на душу населения (3) для заданного значения агрегированных показателей доходов, потребления или перераспределения благ. Умножая найденные подушевые показатели на численность населения, можно получить распределение агрегированных доходов или потребления по всем возрастным группам (4): 


$$
\begin{aligned}
& \bar{x}(\mathrm{a})=\Theta x(a), \\
& \bar{X}(\mathrm{a})=\bar{x}(\mathrm{a}) \mathrm{N}(\mathrm{a}),
\end{aligned}
$$

где:

$\bar{x}($ a) - возрастной профиль NTA (в расчете на душу населения);

$\bar{X}(a)$ - агрегированный профиль NTA в возрасте $a$.

\section{ЭКОНОМИЧЕСКИЙ ЖИЗНЕННЫЙ ЦИКЛ В РОССИИ}

Показатели экономического жизненного цикла можно изучать на микроуровне (поведение индивидуума) и агрегировано - на макроуровне. На макроуровне важнейшим фактором, определяющим особенности жизненного цикла, является возрастная структура населения. Изменения в возрастной структуре ведут к тому, что увеличивается численность той или иной возрастной группы иждивенцев или работников. В зависимости от того, как меняется возрастная структура, население производит или потребляет больше или меньше ресурсов.

Построенные возрастные модели (профили) трудового дохода, потребления и дефицита жизненного цикла для России приведены на рисунке 1. Агрегированные показатели трудовых доходов и потребления отражают особенности возрастной структуры населения.

Агрегированные и подушевые оценки трудовых доходов и потребления позволяют оценить дефицит жизненного цикла и его особенности в отдельные периоды жизни людей (рисунок 1). У населения России «бездефицитный период» начинается в 23 года и продолжается до 56 лет. В большинстве развитых стран (таблица 2) из-за более длительного периода обучения «бездефицитный» период начинается позже. В развивающихся странах он начинается позже из-за отсутствия постоянных источников получения доходов и особенностей взаимоотношений с главами домохозяйств. Более поздний выход на пенсию в развитых странах предполагает и более позднее окончание «бездефицитного» периода по сравнению с Россией. В большинстве развивающихся стран, где отсутствует пенсионная система, время окончания «бездефицитного» периода определяется физиологическими возможностями человека - возрастом, до которого в среднем можно трудиться.

В таблице 3 представлена краткая форма счета экономического жизненного цикла национальных трансфертных счетов России. Обращает внимание высокий уровень общественного потребления по отношению к частному в детских возрастах. В общей сложности дефицит жизненного цикла в России в 2013 г. составил 3473 млрд рублей, что составило порядка $4,7 \%$ ВВП. 


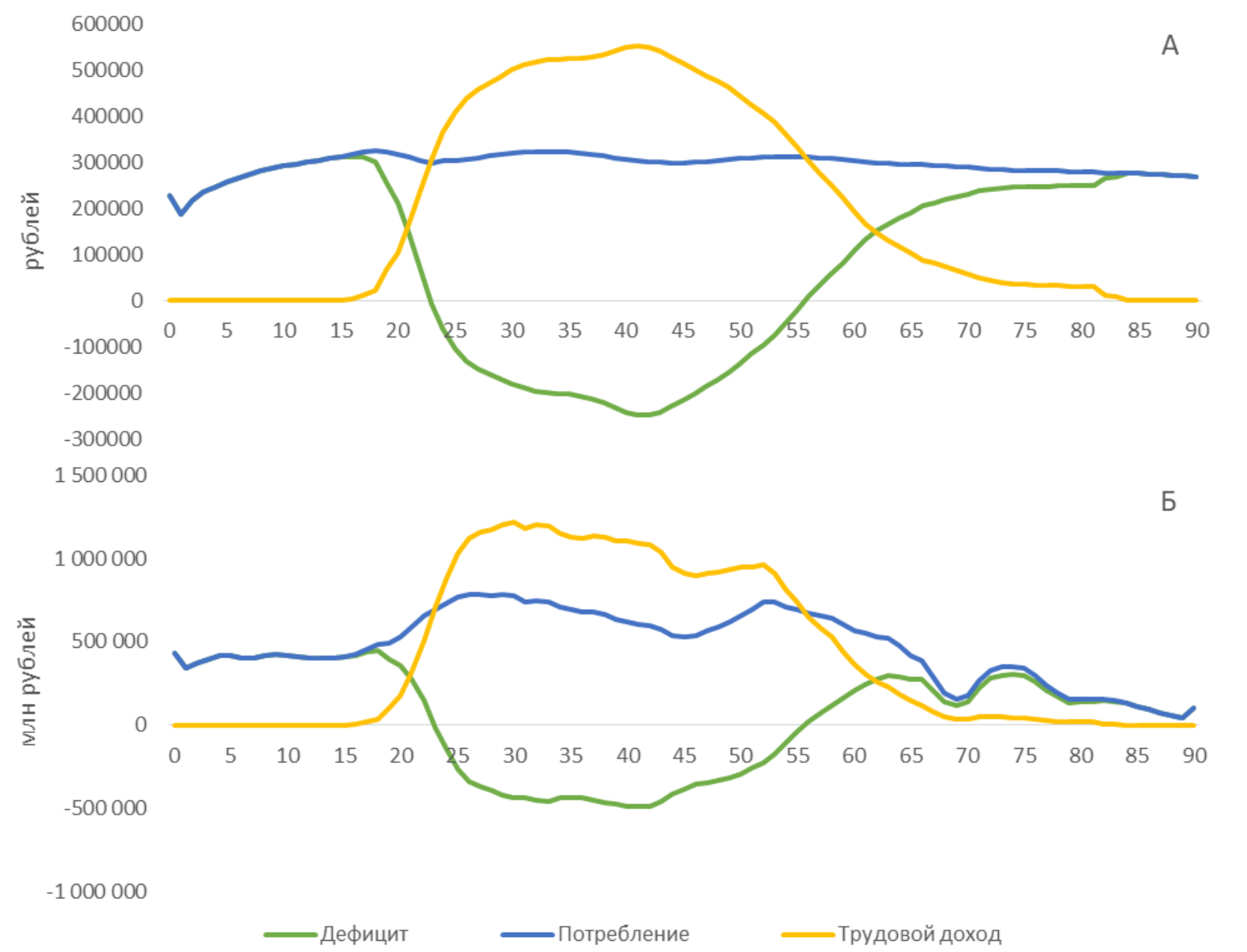

Рисунок 1. Экономический жизненный цикл в России: в расчете на душу населения (А), агрегированный (Б), 2013

Источник: Расчеты авторов.

Таблица 2. Возрастные границы «бездефицитной» стадии жизненного цикла в разных странах мира

\begin{tabular}{l|cc}
\hline Страна (год оценки) & $\begin{array}{c}\text { Нижняя } \\
\text { граница, годы }\end{array}$ & Верхняя граница, годы \\
\hline США (2003) & 25 & 60 \\
Нигерия (2004) & 31 & 57 \\
Германия (2010) & 27 & 49 \\
Мексика (2003) & 32 & 56 \\
Ю. Корея (2000) & 23 & 55 \\
Ю. Корея (2010) & 27 & 55 \\
Россия (2013) & 23 & 5 \\
\hline
\end{tabular}

Источник: NTA Database - URL: http://www.ntaccounts.org (дата обращения: 22.12.2018), для России расчеты авторов.

Одно из важных достоинств NTA состоит в открывающихся возможностях комплексных межстрановых сравнений моделей доходов, потребления и перераспределения ресурсов. Для этого соответствующие показатели необходимо нормализовать. Так, в целях международных сопоставлений возрастные характеристики трудового дохода населения России и сравниваемых стран (рисунок 2) были 
нормализованы посредством их деления на средний доход в возрастах от 30 до 49 лет включительно. Результаты этих сопоставлений показывают, что в отличие от развитых стран, а также некоторых развивающихся стран, пик получения максимального дохода в России приходится на возраст около 40 лет. В таких странах, как США или Германия этот пик наблюдается в предпенсионных возрастах. Возрастная модель получения трудового дохода в России 2013 г. напоминает модель для Южной Кореи 2003 г. (рисунок 2).

Что касается частного потребления, за исключением услуг систем здравоохранения и образования, то его также оценивали по результатам названных выше обследований.

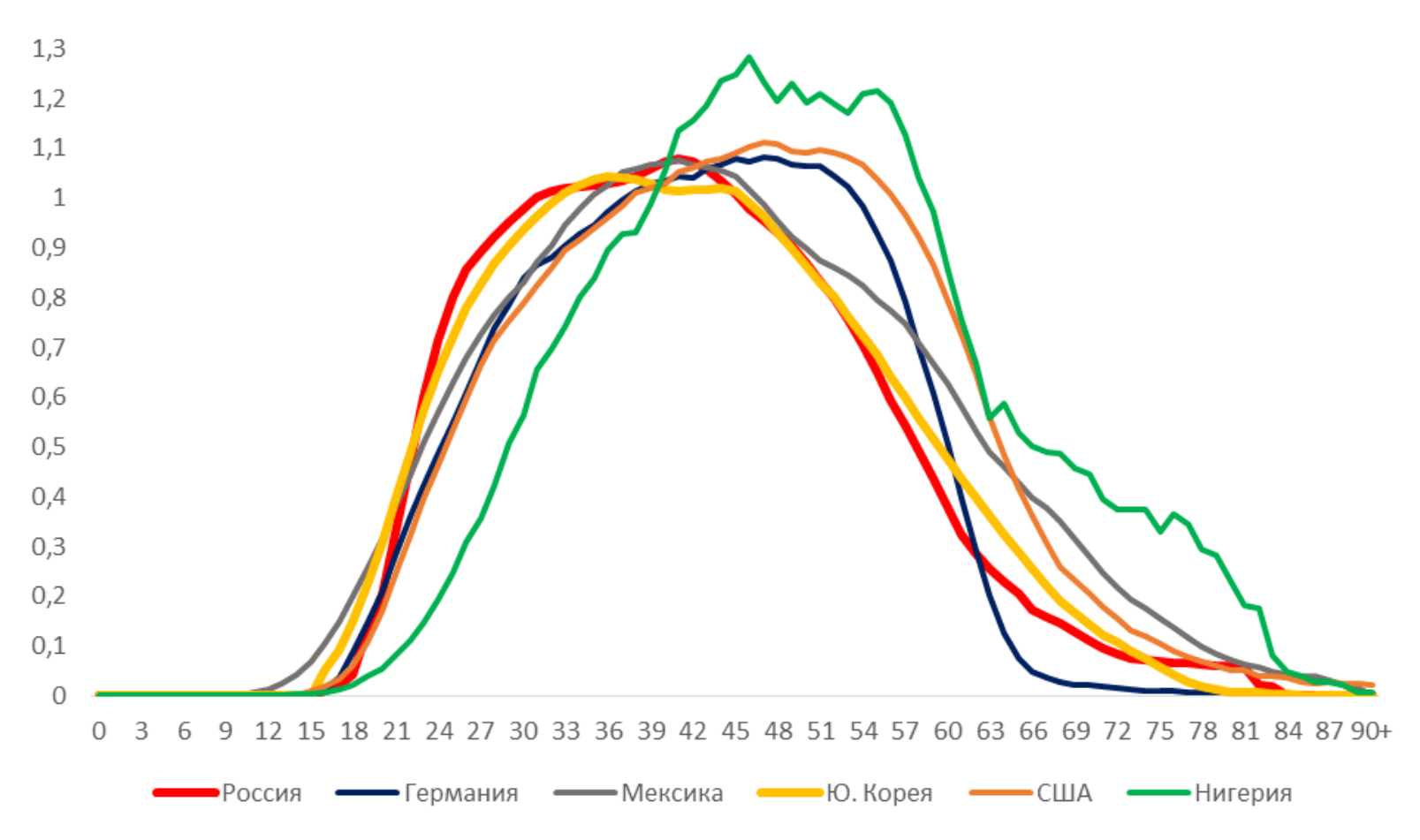

Рисунок 2. Нормализованные показатели дохода (средний доход [30-49 лет] = 1) в расчете на душу населения по некоторым странам мира, 2003-2013

Источник: NTA Database - URL: http://www.ntaccounts.org (дата обращения: 22.12.2018), для России расчеты авторов.

Возрастные профили потребления в расчете на душу населения для некоторых стран мира приведены на рисунке 3. Наивысший уровень потребления в России приходится на юношеские и молодые трудоспособные возраста (рисунок 3 и таблица 2), в развитых странах - на старшие нетрудоспособные возраста, во многом из-за высоких расходов на услуги здравоохранения (как частные, так и государственные). Возрастная модель потребления в России, как и в случае с трудовыми доходами, аналогична южнокорейской модели. Но причины этого сходства нужно еще выяснить. 
Таблица 3. Дефицит жизненного цикла, характеристики доходов и потребления по укрупненным возрастным группам, Россия, 2013

\begin{tabular}{|c|c|c|c|c|c|c|c|c|}
\hline \multirow[b]{2}{*}{ Категории } & \multicolumn{4}{|c|}{$\begin{array}{c}\text { Агрегаты } \\
\text { за год, млрд руб. }\end{array}$} & \multicolumn{4}{|c|}{$\begin{array}{c}\text { В расчете на душу населения } \\
\text { за год, руб. }\end{array}$} \\
\hline & ষ্ল & $\begin{array}{l}\frac{5}{0} \\
\vdots \\
a \\
\vdots \\
0\end{array}$ & 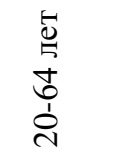 & 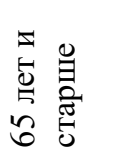 & $\ddot{ల}$ & $\begin{array}{l}5 \\
\vdots \\
a \\
\vdots \\
0\end{array}$ & 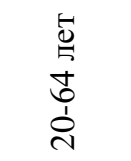 & 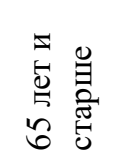 \\
\hline $\begin{array}{l}\text { Дефицит жизненного } \\
\text { цикла }\end{array}$ & 3473 & 8303 & -9282 & 4452 & 24203 & 275335 & -98063 & 238047 \\
\hline Потребление & 43010 & 8320 & 29355 & 5335 & 299706 & 275898 & 310146 & 285255 \\
\hline $\begin{array}{l}\text { Общественное } \\
\text { потребление }\end{array}$ & 13552 & 3997 & 7900 & 1656 & 94434 & 132538 & 83463 & 88520 \\
\hline Образование & 1817 & 1457 & 360 & 0 & 12662 & 48331 & 3799 & 8 \\
\hline Здравоохранение & 2050 & 504 & 1153 & 393 & 14288 & 16724 & 12180 & 21028 \\
\hline Другое & 9684 & 2035 & 6387 & 1262 & 67484 & 67484 & 67484 & 67484 \\
\hline Частное потребление & 29458 & 4323 & 21455 & 3680 & 205271 & 143360 & 226683 & 196735 \\
\hline Образование & 244 & 218 & 25 & 0 & 1700 & 7245 & 268 & 0 \\
\hline Здравоохранение & 1173 & 142 & 745 & 287 & 8174 & 4702 & 7867 & 15321 \\
\hline Другое & 28041 & 3963 & 20685 & 3393 & 195398 & 131413 & 218547 & 181415 \\
\hline Трудовой доход & 39536 & 157 & 38541 & 838 & 275502 & 5219 & 407201 & 44807 \\
\hline Оплата труда & 33811 & 149 & 32871 & 792 & 235606 & 4930 & 347291 & 42331 \\
\hline $\begin{array}{l}\text { Доход от } \\
\text { самозанятости }\end{array}$ & 5725 & 9 & 5670 & 46 & 39896 & 289 & 59910 & 2476 \\
\hline
\end{tabular}

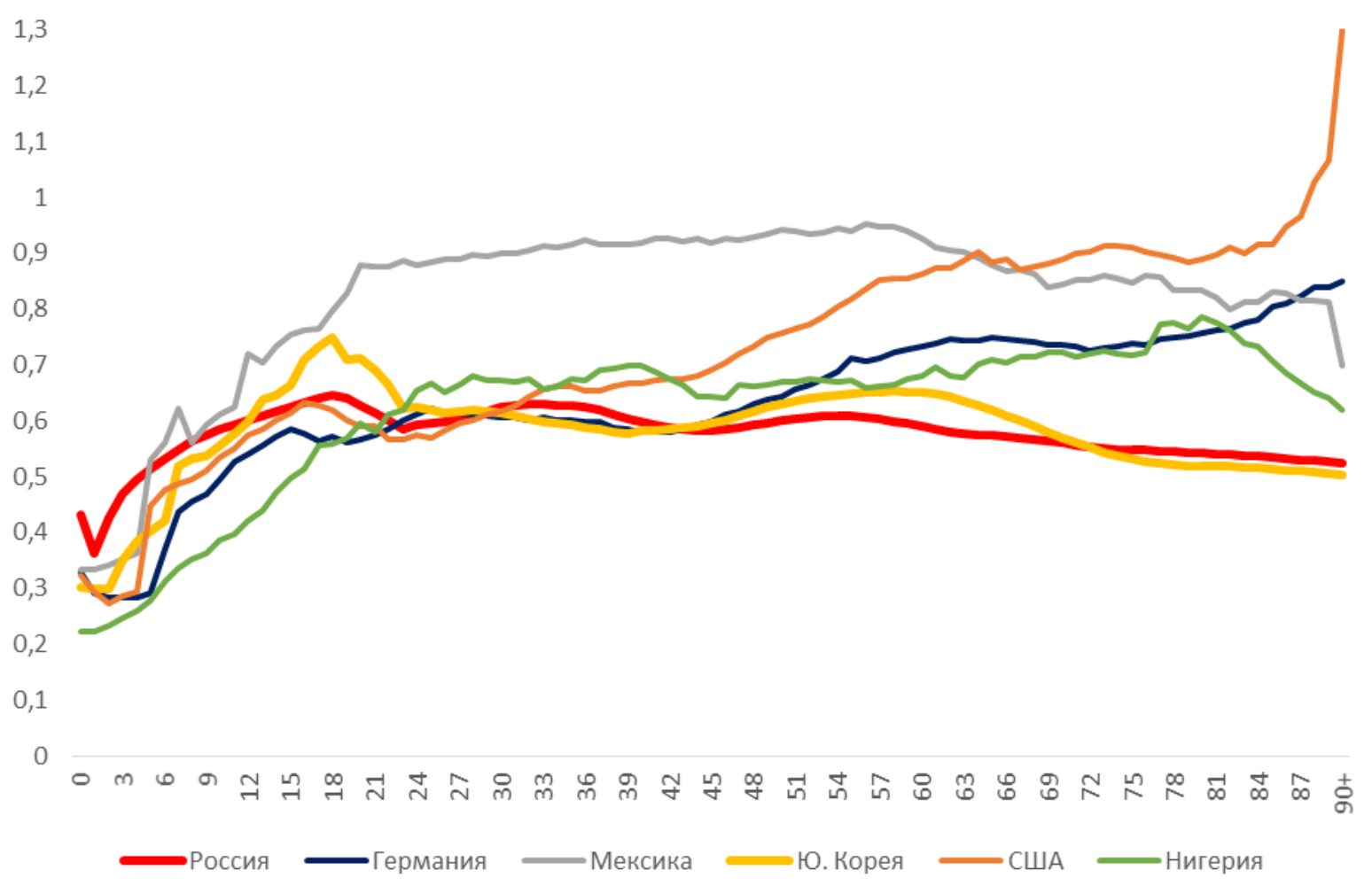

Рисунок 3. Нормализованные показатели потребления в расчете на душу населения (средний доход [30-49 лет] = 1) по некоторым странам мира, 2003-2013

Источник: NTA Database - URL: http://www.ntaccounts.org (дата обращения: 22.12.2018), для России расчеты авторов. 


\section{ДЕФИЦИТ ЖИЗНЕННОГО ЦИКЛА В РОССИИ ДО 2050 ГОДА В УСЛОВИЯХ ДЕМОГРАФИЧЕСКИХ ИЗМЕНЕНИЙ}

Увеличение дефицита жизненного цикла при прочих равных условиях означает, что совокупное потребление все больше превышает совокупные трудовые доходы. Потребление молодых и старших поколений обеспечивается увеличивающимися объемами трансфертов или за счет имеющихся активов. В частности, источником этих поступлений могут быть частные сбережения, поступления из государственного бюджета или внешние заимствования. Уменьшение дефицита свидетельствует об обратном: больше ресурсов в форме социальных трансфертов могут быть направлены в образование и здравоохранение, т.е. инвестироваться в человеческий капитал. Для оценки изменения дефицита жизненного цикла с учетом «демографического фактора» использовалось его отношение к ВВП. При разработке перспективных оценок предполагалось, что дефицит жизненного цикла изменяется под воздействием изменения возрастной структуры. Все экономические параметры (производительность труда, структура экономики, распределительные отношения, возрастные профили доходов и потребления и др.) принимали неизменными. Единственное исключение сделано для случая повышения пенсионного возраста, начиная с 2019 г. (в этом случае допускали изменение возрастного профиля доходов).

Дефицит жизненного цикла по отношению к ВВП оценивался за период с 2017 по 2050 г. ${ }^{6}$ В 2017 г. это отношение составило 4,5\%. Для оценки влияния изменения возрастного состава России на дефицит жизненного цикла мы обратились к трем вариантам демографического прогноза, выполненного в Институте демографии в 2017 г. В так называемый «низкий» вариант прогноза заложены следующие сценарии:

1) медленное снижение смертности по сравнению с уровнем 2017 г.;

2) снижение суммарного коэффициента рождаемости до 1,57 ;

3) небольшой миграционный прирост (в 2050 г. - около 100 тыс. человек в год).

При таких сценариях в период с 2018 по 2050 г. доля населения в возрастах от 65 лет и старше увеличивается с 14,5 до 23\%, доля детей до 15 лет снижается с 18 до 15\%, а доля лиц в рабочем возрастном интервале 15-64 года снижается с 67,5 до 62\%. Согласно второму, «среднему» варианту демографического прогноза, уровень рождаемости повышается до двух рождений у одной женщины, продолжительность жизни при рождении возрастает более чем на 5 лет, миграционный прирост в среднем за год составляет 300 тыс. человек. При таких сценариях доля лиц в старших возрастах увеличивается с 14,5 до 22,5\%, доля детей до 15 лет держится на уровне 18\%, а доля населения в рабочих возрастах снижается до 59,5\%. По высокому варианту прогноза суммарный коэффициент рождаемости увеличивается до уровня, обеспечивающего простое воспроизводство населения (2,1 рождения на одну женщину). Продолжительность жизни прирастает на 7 лет, ежегодный миграционный прирост к 2050 г. возрастает с 300 тыс. до почти 500 тыс.

\footnotetext{
${ }^{6}$ Оценка дефицита жизненного цикла за 2017 г. была выполнена сотрудниками института «Центр развития» НИУ ВШЭ А.Г. Назаровой и А.В. Чернявским в рамках проекта ЦФИ НИУ ВШЭ ТЗ-148 «Включение России в систему международных сопоставлений по национальным поколенческим счетам».
} 
человек. В итоге доля детского населения приближается к 17,7\%, доля лиц в старших возрастах составляет $23,8 \%$, а доля лиц в трудоспособных возрастах $-58,5 \%$.

Дефицит жизненного цикла оценивали при условии постоянства возрастных профилей потребления и трудового дохода. При оценке ВВП, как уже говорилось выше, предполагали, что производительность труда постоянна. Поэтому ВВП изменялся только в результате изменения численности занятого населения (оценки выполняли в постоянных ценах). Прогноз занятого населения также был выполнен в Институте демографии в 2017 г. В итоге ВВП (в неизменных ценах) при низком варианте демографического прогноза уменьшится на 24,5\%, при среднем варианте - на 18,8\%, при высоком варианте - на 15,9\%.

Результаты оценок дефицита жизненного цикла по отношению к ВВП представлены в таблице 4. Как видно, в наибольшей степени дефицит увеличивается в случае высокого (оптимистического) варианта демографического прогноза, в наименьшей - наоборот, в результате низкого или наихудшего сценария демографического развития. В этом нет ничего удивительного, поскольку по низкому варианту прогноза доля лиц в рабочих возрастах максимальна среди всех трех вариантов демографического прогноза. Из-за низкой рождаемости в населении уменьшается доля детских возрастов, относительно высокая смертность тормозит рост числа лиц в пенсионных возрастах. В других вариантах благодаря более высокой рождаемости и низкой смертности увеличивается доля иждивенческих групп. Парадоксальность ситуации заключается в том, что, проводя активную демографическую политику, страна как бы увеличивает дефицит жизненного цикла: требуется больше частных, государственных и, возможно, внешних ресурсов для его покрытия. Но при этом следует помнить, что, в случае низкого варианта демографического прогноза, ВВП (при прочих равных условиях, без учета изменения производительности и инвестиций в капитал) сократится на четверть, в то время как при высоком - только на 15\%.

Таблица 4. Отношение дефицита жизненного цикла к ВВП, \%

\begin{tabular}{|c|c|c|c|c|c|}
\hline Демографический вариант & Экономический вариант & 2017 & 2025 & 2035 & 2050 \\
\hline Низкий & $\begin{array}{l}\text { Неизменная } \\
\text { производительность }\end{array}$ & & 9,4 & 11,7 & 13,5 \\
\hline Средний & $\begin{array}{l}\text { Неизменная } \\
\text { производительность }\end{array}$ & 45 & 10,0 & 13,7 & 16,5 \\
\hline Высокий & $\begin{array}{l}\text { Неизменная } \\
\text { производительность }\end{array}$ & $4, J$ & 10,1 & 13,9 & 18,0 \\
\hline Средний & $\begin{array}{l}\text { Повышение пенсионного } \\
\text { возраста }\end{array}$ & & 3,8 & 5,2 & 7,5 \\
\hline
\end{tabular}

Источник: Расчеты авторов.

Как разрешить этот парадокс? Первое средство - экономический рост. Тем более, что демографические сценарии, заложенные в средний и высокий варианты прогноза, препятствуют (тормозят) убыли населения в трудоспособных возрастах. Предварительные оценки показывают, что в условиях даже умеренного экономического роста прирост дефицита жизненного цикла уменьшится.

Второе решение - повышение пенсионного возраста. Основанием для этого, с демографической точки зрения, служит увеличение продолжительности жизни в старших возрастах, увеличение продолжительности периода обучения и, в результате, удлинение 
периода иждивенчества по отношению к рабочему периоду в жизни людей. Для оценки влияния повышения пенсионного возраста использовался средний вариант демографического прогноза, а также прогноз числа занятых, выполненный в Институте демографии в 2017 г. Предполагалось, что пенсионный возраст повышается на год в течение двух лет, начиная с 2019 г., для мужчин до 65 лет, для женщин до 63 лет (в соответствие с первым проектом Правительства РФ, озвученным в июне 2018 г.). При этом допускали изменение возрастного профиля трудовых доходов, поскольку увеличивается период трудовой активности и вместе с ним, соответственно, повышается уровень доходов в новых предпенсионных, а также постпенсионных возрастных группах. Мы предполагаем, что к концу перехода к новому пенсионному возрасту установится новая модель получения доходов. Новая модель задавалась средним профилем для стран, в которых нормативный пенсионный возраст равен 65 годам у мужчин, 60-65 годам у женщин. Предполагалось, что профиль потребления на протяжении всего прогнозного периода остается неизменным. Отношение дефицита жизненного цикла к ВВП заметно уменьшится именно в период повышения пенсионного возраста - до 3,8\%. Оно начнет увеличиваться только после прекращения этого процесса. Но и в 2050 г. доля дефицита в ВВП будет относительно небольшой: меньше, чем по другим прогностическим вариантам в 2025 г. Очевидно, что в сочетании с экономическим ростом положительный эффект от повышения пенсионного возраста будет еще большим. Уменьшение дефицита открывает дополнительные возможности для частных и государственных инвестиций в человеческий капитал, а также накопления активов.

\section{КОЭФФИЦИЕНТЫ ПОДДЕРЖКИ И ДЕМОГРАФИЧЕСКИЙ ДИВИДЕНД В РОССИИ ДО 2050 гОДА}

Национальные трансфертные счета, рассматривая экономические показатели через призму возраста, измеряют воздействие возрастной структуры населения на экономическую динамику и макропоказатели. По тенденциям в изменении показателей NTA можно косвенно судить об экономических последствиях демографических сдвигов. В данном разделе мы проиллюстрируем «щену старения общества» для экономики, опираясь на так называемые коэффициенты поддержки.

В исследовательской практике в зависимости от целей исследования используют несколько коэффициентов поддержки. Наиболее распространённым в силу доступности данных для его расчетов является коэффициент демографической поддержки, определяемый как отношение числа лиц в рабочих возрастах к числу лиц в иждивенческих возрастах. Коэффициент экономической поддержки можно определить как отношение численности занятого (или экономически активного) населения к численности незанятого населения. Большую популярность в силу эвристических возможностей получил коэффициент эффективной экономической поддержки. Он является полезным индикатором для оценки влияния демографических изменений на экономический рост и измерения демографического дивиденда. Коэффициент эффективной демографической поддержки интегрирует в себе характеристики возрастной структуры и возрастные профили трудового дохода и потребления. 
Для расчета коэффициента эффективной экономической поддержки используют два показателя: эффективного работника и эффективного потребителя [Mason et al 2017: 6]. В качестве последних берут средние значения трудового дохода и потребления на человека в возрастном интервале от 30 до 49 лет включительно. Средние значения рассчитываются как средние арифметические из значений уровней доходов и потребления в однолетних возрастных группах. Эффективное число работников $L(x, t)$ рассчитывается по следующей формуле (5):

$$
\begin{gathered}
L(t)=\sum_{0}^{\omega} \breve{y} l(x) P(x, t), \\
\breve{y} l(x)=y l(x, b) / y l(30-49, b),
\end{gathered}
$$

где:

yl $(\mathrm{x}, \mathrm{b})$ - трудовой доход на человека в возрасте х и в базовый год b;

yl(30-49,b) - среднедушевой доход в возрасте от 30 до 49 лет;

$\mathrm{P}(\mathrm{x}, \mathrm{t})$ - численность населения в возрасте х в момент времени $\mathrm{t}$.

Эффективное число потребителей рассчитывается по аналогичной схеме (формула 6):

$$
\begin{array}{r}
N(t)=\sum_{0}^{\omega} \breve{\mathrm{c}}(x) P(x, t), \\
\breve{\mathrm{c}}(x)=\mathrm{c}(x, b) / \mathrm{c}(30-49, b),
\end{array}
$$

где:

$c(x, b)$ - потребление на человека в возрасте $x$ и в базовый год $b$;

$c(30-49, b)$ - среднедушевое потребление в возрасте от 30 до 49 лет;

$P(x, t)$ - численность населения в возрасте $x$ в момент времени $t$.

Коэффициент эффективной поддержки $S R(t)$ рассчитывается как отношение числа эффективных работников к числу эффективных потребителей (формула 7):

$$
S R(t)=\frac{L(t)}{N(t)} .
$$

Нами были выполнены оценки трех коэффициентов поддержки до 2050 г. (рисунок 4) для среднего варианта демографического прогноза Института демографии НИУ ВШЭ. Как видно, коэффициенты поддержки снижаются. Скорость этого снижения замедлится в силу особенностей изменения возрастной структуры в 2030-х годах. При расчете коэффициента демографической поддержки нижняя граница рабочего возраста определялась возрастом 20 лет, верхняя - 64 года. При расчете эффективной экономической поддержки возрастные профили трудового дохода и потребления не изменялись. Очевидно, что коэффициент демографической поддержки превосходит все остальные. Показатели экономической и эффективной экономической поддержки учитывают тот факт, что часть населения в трудоспособных возрастах не занята или получает небольшой трудовой доход. 


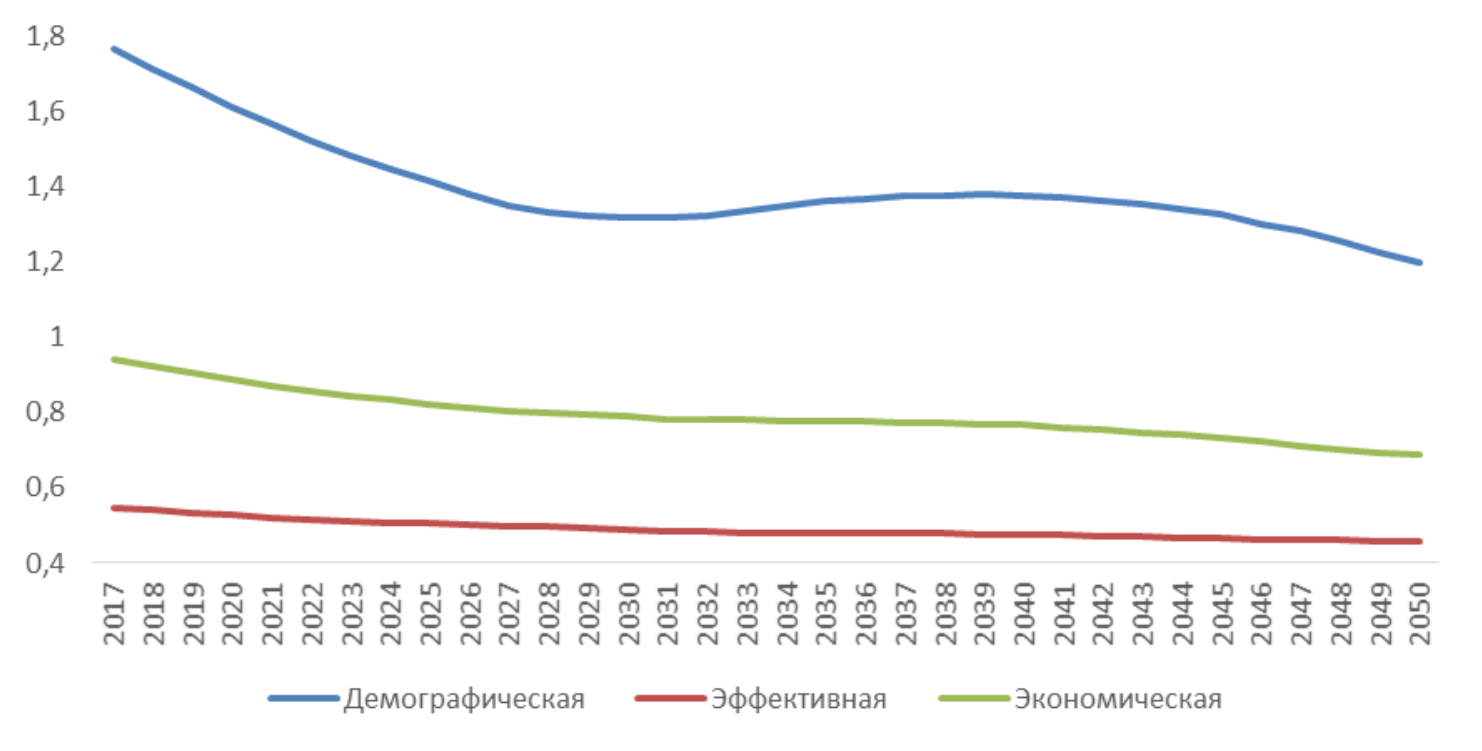

Рисунок 4. Коэффициенты поддержки, Россия, 2017-2050

Источник: Расчеты авторов.

С помощью коэффициента эффективной экономической поддержки можно измерить первый демографический дивиденд и определить его вклад в экономический рост. Первый демографический дивиденд - это выигрыш, который экономика страны может получить в результате оптимизации возрастной структуры из-за снижения иждивенческой (демографической) нагрузки на работающее население в результате снижения рождаемости. Он появляется с увеличением демографической и экономической поддержки и сходит на нет по мере его снижения. Оптимизация возрастной структуры выражается в достижении исторического максимума доли лиц в рабочих возрастах в общей численности населения или исторического минимума демографической нагрузки. Для получения демографического дивиденда необходимы институциональные и экономические условия, обеспечивающие высокую занятость и возможность получения трудового дохода. По оценкам Блума и Уильямсона, около 30\% прироста ВВП в Китае и странах ЮгоВосточной Азии связано с получением демографического дивиденда [Bloom, Williamson 1998].

Простая модель связывает коэффициент эффективной поддержки с первым демографическим дивидендом (формула 8):

$$
\frac{Y(t)}{N(t)}=\frac{Y(t)}{L(t)} S R(t) .
$$

В этом уравнении доход на эффективного потребителя равен производительности, измеряемой отношением $Y(t)$ и $L(t)$, и эффекту изменения возрастной структуры, который измеряется коэффициентом поддержки [Mason et al 2017: 7]. Если предположить, что доля трудового дохода в общем доходе не меняется со временем, тогда относительные изменения в трудовом доходе будут совпадать с относительными (в процентном выражении) изменениями в совокупном доходе. В этом случае можно записать данное выражение в виде формулы (9): 


$$
\operatorname{gr}[Y(t) / N(t)]=\operatorname{gr}[Y(t) / L(t)]+\operatorname{gr}[S R(t)],
$$

где $g r()$ означает коэффициент прироста величины, а $Y(t)$ - совокупный доход.

Первый демографический дивиденд рассчитывается как коэффициент прироста коэффициента поддержки. Его величина прямо измеряет вклад изменения возрастной структуры в экономический рост. На рисунке 5 представлены оценки прироста коэффициента эффективной поддержки при условии реализации трех демографических прогнозов, а также в условиях повышения возраста выхода на пенсию с 2019 г. Вплоть до начала 2030-х годов возрастная структура населения будет вносить отрицательный вклад в экономическую динамику. В настоящее время из-за негативных изменений в возрастном составе темпы роста снижаются примерно на 1,3-1,5\%. При этом в 2019 г. демографический дивиденд, исчисленный вышеназванным методом, достигнет своей минимальной величины. Далее демографический дивиденд будет увеличиваться. Более того, в середине 2030-х годов вклад возрастной структуры может даже стать положительным, так как на рынок труда выйдут сравнительно многочисленные поколения, рожденные в 2007-2016 гг. Наибольший дивиденд получается в условиях низкого демографического прогноза. При его реализации вклад возрастной структуры в экономический рост почти на протяжении всех 2030-х годов будет положительным. Но при этом следует учитывать эффект сокращения численности занятого населения. Как было показано выше, при прочих равных условиях (без учета изменения производительности и инвестиций в капитал) ВВП сократится к 2050 г. по сравнению с 2017 г. почти на четверть. Обращает внимание рост демографического дивиденда в случае повышения пенсионного возраста. Но после окончания этого процесса демографический дивиденд резко снижается, а затем вновь возвращается на прежний тренд. Отклонения от тренда, в частности, связаны с тем, что меняется возрастной профиль трудовых доходов в старших возрастах.

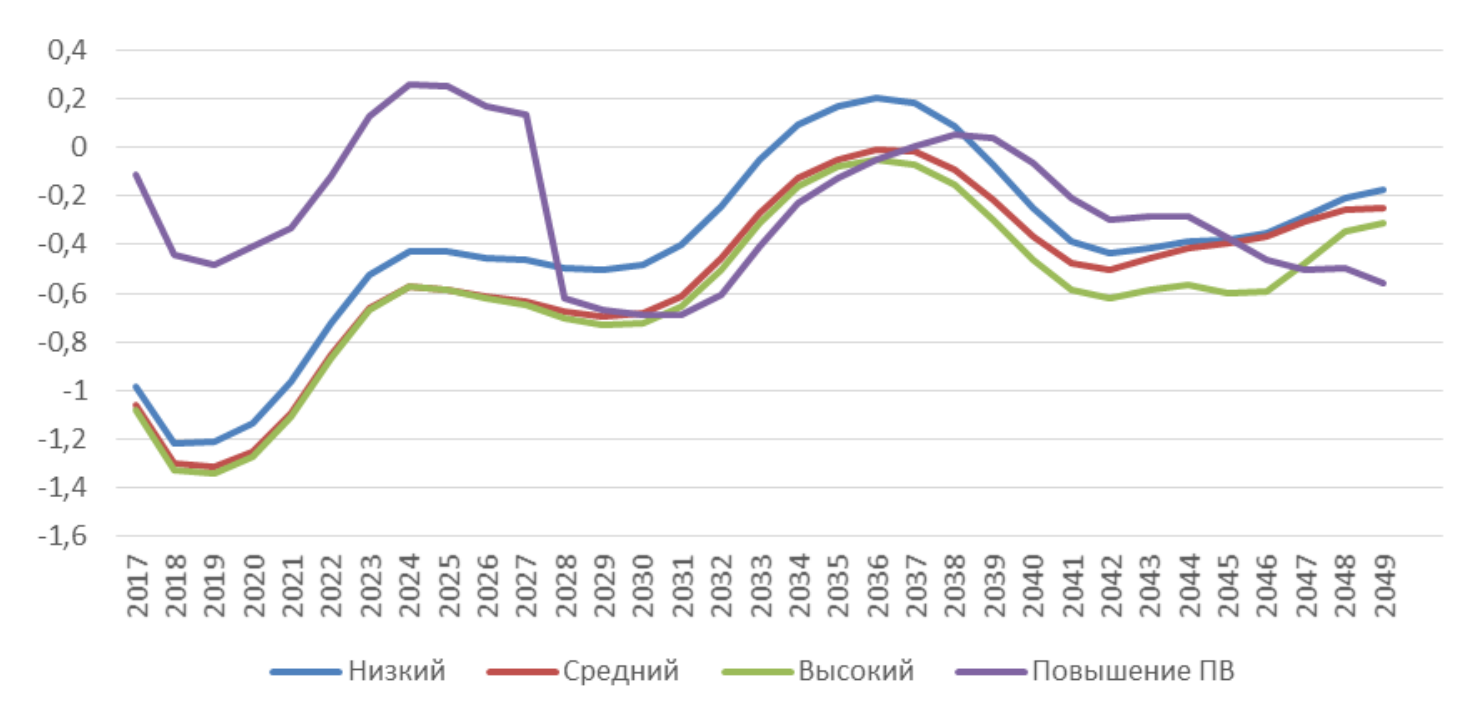

Рисунок 5. Демографический дивиденд для России, 2017-2049, \%

Источник: Расчеты авторов. 
Второй демографический дивиденд реализуется в случае, если демографические изменения ведут к увеличению производительности работников. В условиях действия разнообразных факторов повышения производительности, Р. Ли и А. Мэйсон основное внимание обратили на увеличение капитала [Ли, Мэйсон 2006; 2017]. Основная идея заключается в том, что, по мере старения населения, обеспечение потребления в пенсионный период в меньшей степени опирается на трудовые доходы и в большей степени - на возрастное перераспределение активов и трансферты. Увеличение объемов трансфертов в старших возрастах прямо не влияет на производительность, но увеличение активов, в том числе сбережений, которыми располагают пожилые люди, может вести к увеличению инвестиций в капитал, а потому и к более высокой производительности. Таким образом, демографические изменения могут способствовать более быстрому экономическому росту. Но для этого население должно активно участвовать в разного рода накопительных проектах, а государство - стимулировать это участие и гарантировать сохранность активов. Без этих условий реализация второго демографического дивиденда в России будет невозможна.

\section{ЗАКЛЮЧЕНИЕ}

Процесс старения населения создает множество вызовов для социальных институтов современного общества, сформировавшихся в период «демографической молодости». При принятии решений в социально-экономической сфере учет демографических изменений крайне важен, а оценка их последствий представляется одним из ключевых направлений современных исследований в экономической демографии. Однако, несмотря на значимость демографического фактора, стандартные показатели экономического развития, принятые в современном мире, долгое время разрабатывались в основном по отношению ко всему населению и не отражают вклад отдельных возрастных групп или поколений в совокупное производство и потребление. Выполненные авторами в рамках данной работы расчеты - первая в России попытка оценки вклада различных возрастных групп в производство и распределение национального дохода с помощью системы национальных трансфертных (межпоколенческих) счетов (NTA). В результате оказались возможными расчеты дефицита жизненного цикла, коэффициентов эффективной поддержки и демографического дивиденда в России до 2050 г.

Национальные трансфертные счета представляют собой современную методологию учета влияния демографического фактора на экономику стран. В частности, они делают возможной оценку непростой роли населения старшего возраста в экономическом развитии как потребителей, производителей, инвесторов, получателей и источников трансфертов и др. Выполнить такую оценку с помощью других методов анализа последствий старения в настоящее время не представляется возможным. В рамках стандартной модели национальных трансфертных счетов экономические потоки распределяются по возрастным группам. Развитие такой модели позволяет дезагрегировать эти потоки также по полу, уровню образования и другим характеристикам населения. Более того, современные подходы к их построению позволяют преодолеть одно из ограничений системы национальных счетов, а именно недоучет услуг, которые домохозяйства производят для 
себя. В систему национальных трансфертных счетов нерыночная деятельность членов домашних хозяйств может включаться с помощью показателей использования бюджетов времени в зависимости от возраста. Все это открывает новые перспективы для экономикодемографических исследований в России.

\section{БЛАГОДАРНОСТИ}

Авторы выражают благодарность Роберту Галю (Институт демографии, Венгрия) за ценные рекомендации, А.Г Назаровой и А.В. Чернявскому (Институт «Центр развития» НИУ ВШЭ) за помощь в оценке агрегированных показателей системы национальных трансфертных счетов для России.

\section{ЛИТЕРАТУРА}

Андреев Е.М., Л.Е. Дарский (1986). Экономико-демографические процессы в реальных поколениях // Демографические процессы и их закономерности / Под ред.

А.Г. Волкова М.: Мысль: 10-21.

Барро Р.Д., Х. Сала-и-Мартин (2004). Экономический рост. М.: БИНОМ. Лаборатория знаний. 824 c.

Валкович Э. (1971). Экономические возрастные пирамиды // Марксистско-ленинская теория народонаселения / Под ред. Д.И. Валентея М.: Просвещение: 127-149.

Горюнов Е., Л. Котликофф, С. Синельников-Мурылев (2015). Теоретические основы бюджетного разрыва как показателя долгосрочной фискальной устойчивости и его оценка для России // Научные труды / Ин-т экономической политики им. Е. Т. Гайдара; № 168 P M. 60 c.

Ли Р., Э. Мэйсон (2006). Что такое демографический дивиденд? // Финансы и развитие. URL: https://ntaccounts.org/doc/repository/LM2006_Russian.pdf (дата обращения: 22.12.2018).

Ли Р., Э. Мэйсон (2017). Цена старения // Финансы и развитие. URL: https://www.imf.org/external/russian/pubs/ft/fandd/2017/03/pdf/lee.pdf (дата обращения: 22.12.2018).

Национальные счета России в 2006-2013 годах (2013). Статистический сборник. М.: Росстат. URL:

http://www.gks.ru/wps/wcm/connect/rosstat_main/rosstat/ru/statistics/publications/catalog/do c_1135087050375 (дата обращения: 22.12.2018).

Система национальных счетов 2008 (2012). Европейская комиссия, МВФ, ОЭСР, ООН, Всемирный банк. Нью-Йорк. 827 с.

Сови А. (1977). Общая теория населения. Т.1. М.: Прогресс. 503 с.

Урланис Б.Ц. (1971). Экономические аспекты демографии // Проблемы демографии / Под ред. Д.Л. Бронера и И.Г. Венецкого. М.: 93-110.

Урланис Б.Ц. (1976). Народонаселение, исследование, публицистика. М.: Статистика. $255 \mathrm{c}$.

Чаянов А.В. (1989). Крестьянское хозяйство. Избранные труды. М.: Экономика. 492 с. 
Arthur W.B., G. McNicoll (1978). Samuelson, population and intergenerational transfers // International Economic Review. 241-246.

Auerbach A.J., J. Gokhale, L.J. Kotlikoff (1994). Generational accounting: a meaningful way to evaluate fiscal policy // Journal of Economic Perspectives. 8(1): 73-94.

Barro R.J. (1974). Are government bonds net wealth? // Journal of political economy. 82(6): $1095-1117$.

Bloom D., D. Canning, J. Sevilla (2003). The demographic dividend: a new perspective on the economic consequences of population change. RAND Corporation. $127 \mathrm{c}$.

Bloom D., D. Canning, P. Malaney (2000). Demographic change and economic growth in Asia // Population and Development Review. 26 (Suppl.): 257-290.

Bloom D.E., J.G. Williamson (1998). Demographic transitions and economic miracles in emerging Asia // World Bank Economic Review. 12(3): 419 - 455.

Bommier A., R. Lee, T. Miller, S. Zuber (2010). Who wins and who loses? Public transfer accounts for US generations born 1850 to 2090 // Population and Development Review. 36(1): 1-26.

Caldwell J.C. (1982). Theory of Fertility Decline. New York: Academic Press. 386 c.

D'Albis H., D. Moosa (2015). Generational economics and the national transfer accounts // Journal of Demographic Economics. 81(4): 409-441.

Diamond P. (1965). National debt in neoclassical growth model // The American Economic Review. 55(5): 1126-1150.

Feldstein M. (1974). Social security, induced retirement, and aggregate capital accumulation // Journal of Political Economy. 82(5): 905-926.

Kotlikoff L. (1992). Generational Accounting-Knowing Who Pays, and When, for What we Spend. New York: Free Press. 261 c.

Kotlikoff L.J., L.H. Summers (1981). The role of intergenerational transfers in aggregate capital accumulation // Journal of Political Economy. 89(4): 706-732.

Lee R., A. Mason (2011). Population aging and generational economics: key findings // Population Aging and the Generational Economy / R. Lee, A. Mason, eds. Cheltenham, UK: Edward Elgar Publishing: 3-31.

Lee R., T. Miller (2000). Immigration, social security, and broader fiscal impacts // American Economic Review. 90(2): 350-354.

Lee R., W. Arthur, G. Rodgers (eds) (1988). Economics of Changing Age Distribution in Developed Countries. New York: Oxford University Press. $221 \mathrm{c}$.

Lee R.D. (1980). Aiming at a moving target: Period fertility and changing reproductive goals // Population Studies. 34(2): 205-226.

Lee R.D. (1994). The formal demography of population aging, transfers, and the economic life cycle // Demography of aging: 8-49.

Lee R.D., S. Tuljapurkar (2000). Population forecasting for fiscal planning: Issues and innovations // Demography and Fiscal Policy / A. Auerbach, R. Lee, eds. Cambridge University Press: 7-57.

Mason A. (1988). Saving, economic growth, and demographic change // Population and Development Review. 14: 113-144. 
Mason A., M. Lee, M. Abrigo, S. Lee (2017). Support Ratios and Demographic Dividends: Estimates for the World. New York (NY): Population Division, United Nations. 52 c.

Modigliani F. (1988). The role of intergenerational transfers and life cycle saving in the accumulation of wealth // Journal of Economic Perspectives. 2(2): 15-40.

Modigliani F., R. Brumberg (1954). Utility Analysis and the Consumption Function: An Interpretation of Cross Section Data // Post Keynesian Economics, ed. by K.K.Kurihara. Ruthers University Press New Brunswick New Jersey: 388-436.

Prskawetz A., J. Sambt (2014). Economic support ratios and the demographic dividend in Europe // Demographic Research. 30: 963-1010.

Samuelson P. (1958). An exact consumption loan model of interest with or without the social contrivance of money // Journal of Political Economy. 66(6): 467-482.

Temple J., J. Rice, P. McDonald (2017). Economics of ageing feature. Ageing and the economic life cycle: The national transfer accounts approach // Australian Journal of Aging. 36(4): 271-278.

United Nations (2013). National Transfer Accounts Manual: Measuring and Analysing the Generational Economy. New-York: United Nations.

Willis R.J. (1988). Life cycles institutions and population growth: a theory of the equilibrium interest rate in an overlapping generations model // Economics of Changing Age Distribution in Developed Countries / R. Lee, W. Arthur, G. Rodgers, eds. New York: Oxford University Press: 106-138. 


\title{
GENERATIONAL ACCOUNTS AND DEMOGRAPHIC DIVIDEND IN RUSSIA
}

\author{
MIKHAIL DENISENKO, VLADIMIR KOZLOV
}

\begin{abstract}
The paper presents a modern methodology for estimating the impact of different age groups on the production and distribution of national income, called national transfer (generational) accounts. The human economic lifecycle is divided into stages defined by the ratio of labour income to consumption. In middle ages the gained income is higher than current consumption. The resulting surplus of resources is supposed to cover the income deficit in older and younger age groups. Estimates of the deficit or surplus at different ages are made for the Russian population for 2013 based on the results of age profiles taken from administrative sources and surveys. In the paper we also estimate the projected changes in the lifecycle deficit under different demographic development scenarios. Age profiles of labour income and consumption are used to calculate the effective economic support and the influence of demographic changes in Russia on economic growth rates in the near future.
\end{abstract}

Key words: economic lifecycle, national transfer accounts, income, consumption, ageing, effective economic support, demographic dividend.

\begin{abstract}
Mikhail Denisenko (mdenissenko@hse.ru), NATIOnAl Research University Higher School of Economics, RUSSIA.

Vladimir Kozlov (vakozlov@hse.ru), NATIONAL RESEARCH UNIVERSiTy HighER SCHOOl of EcONOMICS, RUSSIA.

THE PAPER WAS PREPARED WITHIN THE FRAMEWORKS OF THE NRU HSE APPLIED RESEARCHES PROJECTS. TZ 148 "THE ENTRANCE OF RUSSIA INTO THE SYSTEM OF INTERNATIONAL COMPARISONS BASED ON NTA"
\end{abstract}

DATE RECEIVED : OCTOBER 2018.

\section{REFERENCES}

Andreev E.M., L.E. Darsky (1986). Ekonomiko-demograficheskie protsessy v real'nykh pokoleniyakh [Economic and demographic processes in generations] // Demograficheskie protsessy i ikh zakonomernosti [Demographic processes and their patterns] / A.G. Volkov, ed. Moscow: Mysl': 10-21.

Arthur W.B., G. McNicoll (1978). Samuelson, population and intergenerational transfers // International Economic Review. 241-246.

Auerbach A.J., J. Gokhale, L.J. Kotlikoff (1994). Generational accounting: a meaningful way to evaluate fiscal policy // Journal of Economic Perspectives. 8(1): 73-94.

Barro R.D., X. Sala-i-Martin (2004). Ekonomicheskiy rost [Economic growth]. Moscow: BINOM. Laboratoriya znaniy. 824 p.

Barro R.J. (1974). Are government bonds net wealth? // Journal of Political Economy. 82(6): 1095-1117.

Bloom D., D. Canning, J. Sevilla (2003). The demographic dividend: a new perspective on the economic consequences of population change. RAND Corporation. $127 \mathrm{p}$.

Bloom D., D. Canning, P. Malaney (2000). Demographic change and economic growth in Asia // Population and Development Review. 26 (Suppl.): 257-290.

Bloom D.E., J.G. Williamson (1998). Demographic transitions and economic miracles in emerging Asia // World Bank Economic Review. 12(3): 419 - 455. 
Bommier A., R. Lee, T. Miller, S. Zuber (2010). Who wins and who loses? Public transfer accounts for US generations born 1850 to 2090 // Population and Development Review. 36(1): 1-26.

Caldwell J.C. (1982). Theory of Fertility Decline. New York: Academic Press. 386 p.

Chayanov A. (1989). Krest'yanskoe khozyaystvo [Peasant economy]. Izbrannye trudy [Selected works]. Moscow: Economica. 492 p.

D'Albis H., D. Moosa (2015). Generational economics and the national transfer accounts // Journal of Demographic Economics. 81(4): 409-441.

Diamond P. (1965). National debt in neoclassical growth model // The American Economic Review. 55(5): 1126-1150.

Feldstein M. (1974). Social security, induced retirement, and aggregate capital accumulation // Journal of Political Economy. 82(5): 905-926.

Goryunov E., L. Kotlikoff, S. Sinelnikov-Murylev (2015). Teoreticheskie osnovy byudzhetnogo razryva kak pokazatelya dolgosrochnoy fiskal'noy ustoychivosti i ego otsenka dlya Rossii [Theoretical foundations of fiscal gap as a long-term fiscal sustainability indicator and its estimates for Russia]. Moscow: Institut ekonomicheskoy politiki im. E.T. Gaydara: 60 p.

Kotlikoff L. (1992). Generational Accounting-Knowing Who Pays, and When, for What we Spend. New York: Free Press. 261 p.

Kotlikoff L.J., L.H. Summers (1981). The role of intergenerational transfers in aggregate capital accumulation // Journal of Political Economy. 89(4): 706-732.

Lee R., A. Mason (2006). Chto takoe demograficheskiy dividend? [What does it mean demographic dividend?] // Finansy i razvitie [Finance and Development]. URL: https://ntaccounts.org/doc/repository/LM2006_Russian.pdf (accessed: 22.12.2018).

Lee R., A. Mason (2011). Population aging and generational economics: key findings // Population Aging and the Generational Economy / R. Lee, A. Mason, eds. Cheltenham, UK: Edward Elgar Publishing: 3-31.

Lee R., A. Mason (2017). Tsena stareniya [Cost of aging] // Finansy i razvitie [Finance and Development]. URL: https://www.imf.org/external/russian/pubs/ft/fandd/2017/03/pdf/lee.pdf (accessed: 22.12.2018).

Lee R., T. Miller (2000). Immigration, social security, and broader fiscal impacts // American Economic Review. 90(2): 350-354.

Lee R., W. Arthur, G. Rodgers (eds) (1988). Economics of Changing Age Distribution in Developed Countries. New York: Oxford University Press. 221 p.

Lee R.D. (1980). Aiming at a moving target: Period fertility and changing reproductive goals // Population Studies. 34(2): 205-226.

Lee R.D. (1994). The formal demography of population aging, transfers, and the economic life cycle // Demography of aging: 8-49.

Lee R.D., S. Tuljapurkar (2000). Population forecasting for fiscal planning: Issues and innovations // Demography and Fiscal Policy / A. Auerbach, R. Lee, eds. Cambridge University Press: 7-57.

Mason A. (1988). Saving, economic growth, and demographic change // Population and Development Review. 14: 113-144. 
Mason A., M. Lee, M. Abrigo, S. Lee (2017). Support Ratios and Demographic Dividends: Estimates for the World. New York (NY): Population Division, United Nations. 52 p.

Modigliani F. (1988). The role of intergenerational transfers and life cycle saving in the accumulation of wealth // Journal of Economic Perspectives. 2(2): 15-40.

Modigliani F., R. Brumberg (1954). Utility Analysis and the Consumption Function: An Interpretation of Cross Section Data // Post Keynesian Economics, ed. by K.K.Kurihara. Ruthers University Press New Brunswick New Jersey: 388-436.

Natsional'nye scheta Rossii v 2006-2013 godakh [National Accounts in Russia in 2006-2013] (2013). Statisticheskiy sbornik [Statistical Yearbook]. Moscow: Rosstat. URL: http://www.gks.ru/wps/wcm/connect/rosstat_main/rosstat/ru/statistics/publications/catalog/do c_1135087050375 (accessed: 22.12.2018).

Prskawetz A., J. Sambt (2014). Economic support ratios and the demographic dividend in Europe // Demographic Research. 30: 963-1010.

Samuelson P. (1958). An exact consumption loan model of interest with or without the social contrivance of money // Journal of Political Economy. 66(6): 467-482.

Sauvy A. (1977). Obshchaya teoriya naseleniya [General population theory]. T.1. [V.1]. Moscow: Progress. 503 p.

Sistema natsional'nykh schetov 2008 [System of national accounts 2008] (2012). UN, European Commission, IMF, OECD, World Bank. New York. 827 p.

Temple J., J. Rice, P. McDonald (2017). Economics of Ageing Feature. Ageing and the economic life cycle: The National Transfer Accounts approach // Australian Journal of Aging. 36(4): 271-278.

United Nations (2013). National transfer accounts manual: Measuring and analysing the generational economy. New-York: United Nations.

Urlanis B.C. (1971). Ekonomicheskie aspekty demografii [Economic aspects of demography] // Problemy demografii [Demographic problems] // D.L. Broner, I.G. Venetskiy, eds. Moscow: 93-110.

Urlanis B.C. (1976). Narodonaselenie, issledovanie, publitsistika [Population, researches and essays]. Moscow: Statistika. 255 p.

Valkovics E. (1971). Ekonomicheskie vozrastnye piramidy [Economic age pyramids] // Marksistsko-leninskaya teoriya narodonaseleniya [Marx-Lenin population theory] / D. Valentei, ed. Moscow: Prosveshchenie: 127-149.

Willis R.J. (1988). Life cycles institutions and population growth: a theory of the equilibrium interest rate in an overlapping generations model // Economics of Changing Age Distribution in Developed Countries / R. Lee, W. Arthur, G. Rodgers, eds. New York: Oxford University Press: 106-138. 